\title{
Should we start debating medical ethics in our daily practice?
}

\author{
Omran Bakoush \\ Department of Renal Medicine, Lund University Hospital, Sweden
}

To the Editor: In response to Dr EA Elkhammas editorial In December 2006 of ljm [1], I remembered an incident that happened to one of our colleagues several years ago. My friend was practicing in Libya when he saw a non Libyan patient who is in need for dialysis. This patient was living in Libya with her married daughter for many years. My friend declined to accept this patient in his chronic dialysis program. Due to high expenses of dialysis, he argued that the patient should receive her dialysis treatment in her home country and not to compete with the Libyan citizens. The physician was determined not to change his decision despite the refusal of the patient to go back to her home country. Fortunately, the patient was accepted in a different dialysis program and the stand off was over.

Few years later the same doctor witnessed a similar situation while working in a European country. He came across a female in her forties who developed acute but permanent renal failure as a result of mushroom poisoning (Cortinarius species). The responsible physician asked the patient about the possibly for dialysis treatment in her home country. He quickly realized that there are no dialysis facilities in his patient's home country and sending her back will be risking her life. Without any hesitation, he wrote a letter to the department of immigration recommending giving this patient residency status in this country. He made that recommendation based on his ethical and moral behaviour as a physician. He knew that her life is at danger by sending her back to her home country where there is no adequate dialysis facilities. The patient obtained her residence permit and received the life saving treatment and was placed on the waiting list for kidney transplantation as any other citizen of the country. She received a kidney transplant and currently is doing very well.

These two stories made an outstanding ethical lesson for this doctor who felt that his medical education was lacking the ethical part. This physician remembered that he acted based on his biased cultural knowledge at that time with no ethical principles. Several years later, he was taught by the European physician that doctors have an ethical code that dictates their conduct and direct it toward human benefit. This physician did not hesitate to add this patient to the busy dialysis program and did not think that she is going to have expensive treatment within a limited space.

The lack of use and consideration of medical ethics during discussing the patient's medical and social problems is a big gap in Libyan medicine. Usually our decision is influenced primarily by the cultural and emotional background and personal attitude. If medical ethics were considered, I am sure that the first case would have been treated differently. In general who lack the knowledge can not practice it.

I think we will learn a lot if we ask our selves all the time this simple question, is there any violence to medical ethics in my decision? Should we start debating medical ethics in our daily practice? Yes, we should start debating medical ethics in our daily practice.

\section{References}

1. Elkhammas EA. Medical ethics in Libya: where to start? Libyan J Med, AOP:061201; 2006: $1(2)$. 